\title{
Endocannabinoids Inhibit Transmission at Granule Cell to Purkinje Cell Synapses by Modulating Three Types of Presynaptic Calcium Channels
}

\author{
Solange P. Brown, Patrick K. Safo, and Wade G. Regehr \\ Department of Neurobiology, Harvard Medical School, Boston, Massachusetts 02115
}

\begin{abstract}
At many central synapses, endocannabinoids released by postsynaptic cells inhibit neurotransmitter release by activating presynaptic cannabinoid receptors. The mechanisms underlying this important means of synaptic regulation are not fully understood. It has been shown at several synapses that endocannabinoids inhibit neurotransmitter release by reducing calcium influx into presynaptic terminals. One hypothesis maintains that endocannabinoids indirectly reduce calcium influx by modulating potassium channels and narrowing the presynaptic action potential. An alternative hypothesis is that endocannabinoids directly and selectively inhibit N-type calcium channels in presynaptic terminals. Here we test these hypotheses at the granule cell to Purkinje cell synapse in cerebellar brain slices. By monitoring optically the presynaptic calcium influx $\left(\mathrm{Ca}_{\text {influx }}\right)$ and measuring the EPSC amplitudes, we found that cannabinoid-mediated inhibition arises solely from reduced presynaptic $\mathrm{Ca}_{\text {influx }}$. Next we found that cannabinoid receptor activation does not affect the time course of presynaptic calcium entry, indicating that the reduced $\mathrm{Ca}_{\text {influx }}$ reflects inhibition of presynaptic calcium channels. Finally, we assessed the classes of presynaptic calcium channels inhibited by cannabinoid receptor activation via peptide calcium channel antagonists. Previous studies established that N-type, $\mathrm{P} / \mathrm{Q}$-type, and R-type calcium channels are all present in granule cell presynaptic boutons. We found that cannabinoid activation reduced $\mathrm{Ca}_{\text {influx }}$ through $\mathrm{N}$-type, $\mathrm{P} / \mathrm{Q}$-type, and R-type calcium channels to 29,60 , and $55 \%$ of control, respectively. Thus, rather than narrowing the presynaptic action potential or exclusively modulating N-type calcium channels, CB1 receptor activation inhibits synaptic transmission by modulating all classes of calcium channels present in the presynaptic terminal of the granule cell to Purkinje cell synapse.
\end{abstract}

Key words: calcium channels; cannabinoids; Purkinje cell; DSI; DSE; cerebellum

\section{Introduction}

The endocannabinoid signaling system allows neurons to modulate transiently the strength of their inputs by inhibiting synaptic transmission (Kreitzer and Regehr, 2001a; Ohno-Shosaku et al., 2001; Wilson and Nicoll, 2001). Endocannabinoids such as anandamide and 2-arachidonylglycerol (2-AG) (Devane et al., 1992; Di Marzo et al., 1994; Stella et al., 1997) are released from the postsynaptic neuron. They activate presynaptic G-proteincoupled cannabinoid receptors, leading to a transient inhibition of excitatory and inhibitory synaptic transmission (Kreitzer and Regehr, 2001a,b; Maejima et al., 2001; Ohno-Shosaku et al., 2001; Wilson and Nicoll, 2001; Diana et al., 2002; Yoshida et al., 2002). Cannabinoid receptors are distributed widely throughout the

Received March 12, 2004; revised May 5, 2004; accepted May 6, 2004

This work was supported by National Institutes of Health Grants R01 NS 32405 and R01 NS 44396. We thank M. Beierlein, D. Blitz, S. Brenowitz, K. Foster, A. Kreitzer, and M. Xu-Friedman for comments on this manuscript.

Correspondence should be addressed to Wade Regehr, Goldenson 308, Department of Neurobiology, Harvard Medical School, 220 Longwood Avenue, Boston, MA 02115. E-mail: wade_regehr@hms.harvard.edu.

S. P. Brown's present address: Department of Comparative Medicine, Stanford University School of Medicine, Edwards Building R314, 300 Pasteur Drive, Stanford, CA 94305-5342.

DOI:10.1523/JNEUROSCI.0918-04.2004

Copyright $\odot 2004$ Society for Neuroscience $\quad 0270-6474 / 04 / 245623-09 \$ 15.00 / 0$ brain, and such retrograde signaling has been observed at numerous synapses (Elphick and Egertova, 2001; Kreitzer and Regehr, 2002; Wilson and Nicoll, 2002).

A reduction in presynaptic calcium influx $\left(\mathrm{Ca}_{\text {influx }}\right)$ leading to a decrease in neurotransmitter release has been implicated in cannabinoid-mediated synaptic modulation, but it is not clear how $\mathrm{Ca}_{\text {influx }}$ is reduced. In cell culture and expression systems it has been shown that activation of $\mathrm{CB} 1$ receptors can modulate many types of channels, including several classes of potassium and calcium channels (Ameri, 1999; Alger, 2002), presenting many potential targets for physiological cannabinoid receptor activation. One possibility is that potassium channel modulation shortens the duration of the action potential and thereby indirectly reduces $\mathrm{Ca}_{\text {influx }}$. The primary evidence for this hypothesis is that potassium channel antagonists such as 4-aminopyridine (4AP) and barium eliminate or decrease the inhibition following cannabinoid receptor activation (Alger et al., 1996; Daniel and Crepel, 2001; Robbe et al., 2001; Diana and Marty, 2003). However, cannabinoids do not appear to affect extracellular recordings of the presynaptic volley (Levenes et al., 1998; Takahashi and Linden, 2000), which are sensitive to changes in the presynaptic waveform (Sabatini and Regehr, 1997), making it unclear how modulation of potassium channels could contribute to decreased $\mathrm{Ca}_{\text {influx}}$. 
Another proposed mechanism is direct modulation of presynaptic calcium channels (Sullivan, 1999; Hoffman and Lupica, 2000; Kreitzer and Regehr, 2001a; Alger, 2002). Specifically, several recent studies have suggested that $\mathrm{N}$-type calcium channels play a privileged role in cannabinoid-mediated inhibition (Alger, 2002). For example, cannabinoid-mediated modulation of hippocampal inhibitory synapses is not affected by blockers of $\mathrm{P} / \mathrm{Q}-$ type calcium channels but is eliminated by $\mathrm{N}$-type calcium channel antagonists (Lenz et al., 1998; Wilson et al., 2001). Similarly, cannabinoid-mediated inhibition of excitatory synapses onto both striatal neurons (Huang et al., 2001) and trigeminal caudal neurons (Liang et al., 2004) is eliminated primarily by pretreatment with $\mathrm{N}$-type calcium channel antagonists. These results suggest that selective regulation of $\mathrm{N}$-type calcium channels may be a general mechanism for endocannabinoid-mediated retrograde inhibition.

We tested these hypotheses by determining the mechanism responsible for cannabinoid-mediated inhibition of transmission at the granule cell to Purkinje cell synapse. This synapse is well suited to these studies because it is highly sensitive to retrograde signaling by endocannabinoids (Kreitzer and Regehr, 2001a) and because the calcium channels responsible for transmitter release are known. Transmission at this synapse is mediated by three pharmacologically separable classes of calcium channels: N-type, P/Q-type, and R-type (Mintz et al., 1995; Dittman and Regehr, 1996; Sabatini and Regehr, 1997). We found that cannabinoid receptor activation inhibited neurotransmitter release by reducing $\mathrm{Ca}_{\text {influx }}$. The time course of calcium entry was unaltered, indicating that narrowing of the presynaptic action potential did not contribute to reduced $\mathrm{Ca}_{\text {influx }}$. Moreover, we found that, rather than selectively modulating N-type calcium channels, CB1 receptor activation inhibited all classes of calcium channels present in the presynaptic terminal.

\section{Materials and Methods}

Transverse slices (300 $\mu \mathrm{m}$ thick) were cut from the cerebellar vermis of 12- to 17-d-old Sprague Dawley rats in an ice-cold sucrose solution containing (in $\mathrm{mm}$ ): $79 \mathrm{NaCl}, 23 \mathrm{NaHCO}_{3}, 68$ sucrose, $2.3 \mathrm{KCl}, 1.1$ $\mathrm{NaH}_{2} \mathrm{PO}_{4}, 6.4 \mathrm{MgCl}_{2}$, and $0.5 \mathrm{CaCl}_{2}$ bubbled with $95 \% \mathrm{O}_{2} / 5 \% \mathrm{CO}_{2}$. After incubation for $20 \mathrm{~min}$ at $32^{\circ} \mathrm{C}$ the slices were transferred to a saline solution containing (in mM): $125 \mathrm{NaCl}, 26 \mathrm{NaHCO}_{3}, 1.25 \mathrm{NaH}_{2} \mathrm{PO}_{4}, 2.5$ $\mathrm{KCl}, 1 \mathrm{MgCl}_{2}, 2 \mathrm{CaCl}_{2}$, and 25 glucose, bubbled with $95 \% \mathrm{O}_{2} / 5 \% \mathrm{CO}_{2}$ at $32^{\circ} \mathrm{C}$ for an additional $20-40 \mathrm{~min}$; they subsequently were maintained at room temperature. Experiments were performed at room temperature in the presence of bicuculline $(20 \mu \mathrm{M})$ to block inhibitory currents mediated by $\mathrm{GABA}_{\mathrm{A}}$ receptors. AM251 and methanandamide were purchased from Tocris Cookson (Ellisville, MO). $\omega$-Conotoxin GVIA and $\omega$-agatoxin IVA were purchased from Bachem (King of Prussia, PA), Alamone (Jerusalem, Israel), and Peptides International (Louisville, KY). All other chemicals were purchased from Sigma/RBI (St. Louis, MO). All procedures involving animals were approved by the Harvard Medical Area Standing Committee on Animals.

Electrophysiological recordings. Whole-cell voltage-clamp recordings of visualized Purkinje cells were obtained as previously described (Regehr and Mintz, 1994) by using an Axopatch 200B (Axon Instruments, Foster City, CA). Glass electrodes (1-2 M $\Omega$ ) were filled with an internal solution containing (in mM): 35 CsF, 100 CsCl, 10 EGTA, 10 HEPES, 0.1 D600, pH 7.3, $300 \mathrm{mOsm}$. Synaptic currents were monitored at a holding potential of $-40 \mathrm{mV}$. Access resistance and leak currents were monitored continuously, and the experiment was terminated if either changed significantly.

$\mathrm{Ca}^{2+}$ imaging. In separate experiments parallel fibers were loaded with magnesium green AM or mag-fura-5 AM (Molecular Probes, Eugene, OR) as previously described (Regehr, 2000) and stimulated with an extracellular glass electrode placed in the molecular layer. For measure- ments using magnesium green, fluorescence intensity was measured with a photodiode on an upright microscope with a 470DF40 excitation filter (Zeiss, Thornwood, NY) and a 515DCLP dichroic and a 530LP emission filter (Omega Optical, Brattleboro, VT). For measurements using magfura-5, a 380DF15 excitation filter, a 435DRLP dichroic filter, and a 455LP emission filter (Omega Optical) were used.

Field potential recordings. To measure the presynaptic volleys, we placed an electrode (2-3 M $\Omega$ ) filled with external solution in the molecular layer, $\sim 100 \mu \mathrm{m}$ from the location being monitored optically and away from the stimulation site. In addition to $20 \mu \mathrm{M}$ bicuculline, $5 \mu \mathrm{M}$ NBQX was added to the external solution to prevent contamination of the signal by synaptic currents.

Data acquisition and analysis. All signals were digitized with a 16-bit analog-to-digital converter (Instrutech, Great Neck, NY) and Pulse Control software (Herrington and Bookman, 1995). EPSCs were filtered at 1 $\mathrm{kHz}$ and digitized at $5 \mathrm{kHz}$. Presynaptic volleys were filtered at $5 \mathrm{kHz}$ and digitized at $50 \mathrm{kHz}$. Photodiode currents were filtered digitally at $300 \mathrm{~Hz}$ and digitized at $5 \mathrm{kHz}$ and or were filtered at $2 \mathrm{kHz}$ (Frequency Devices, Haverhill, MA) and digitized at $50 \mathrm{kHz}$. The $\mathrm{Ca}^{2+}$-dependent fluorescent signals were expressed as the change in fluorescence divided by the unstimulated fluorescence $(\Delta F / F)$. All analysis was performed by using custom macros written in IgorPro (Wavemetrics, Lake Oswego, OR). Averages are given as the mean \pm SEM.

\section{Results}

We first examined whether a reduction in presynaptic $\mathrm{Ca}_{\text {influx }}$ accounts for the cannabinoid-mediated inhibition of excitatory synaptic transmission at the granule cell to Purkinje cell synapse. Parallel fibers were stimulated extracellularly, and the resulting EPSCs were measured in Purkinje cells in whole-cell voltageclamp mode. In separate experiments presynaptic $\mathrm{Ca}_{\text {influx }}$ was quantified with the low-affinity calcium indicator, magnesium green, which provides a linear measure of changes in presynaptic $\mathrm{Ca}_{\text {influx }}$ (Regehr, 2000). The cannabinoid receptor agonist WIN55,212-2 (5 $\mu \mathrm{M})$ reduced both the EPSC amplitude and presynaptic $\mathrm{Ca}_{\text {influx }}$. A representative experiment shows the effect of WIN55,212-2 on EPSCs (Fig. 1A). On average, the EPSC was suppressed to $12 \pm 4 \%$ of control $(n=4)$. WIN55,212-2 also decreased $\mathrm{Ca}_{\text {influx }}$ (Fig. $1 \mathrm{~B}$ ). On average, peak $\mathrm{Ca}_{\text {influx }}$ was decreased to $42 \pm 3 \%$ of control $(n=6)$.

We next determined the relationship between EPSC amplitude and $\mathrm{Ca}_{\text {influx }}$ during cannabinoid modulation. We first evaluated the feasibility of determining a dose-response curve for the effects of WIN55,212-2 on both EPSC amplitude and $\mathrm{Ca}_{\text {influx }}$. We were, however, concerned that the highly lipophilic property shared by endocannabinoid receptor agonists and antagonists would interfere with their penetration into the slice preparation. We therefore took advantage of the predictable anatomy of parallel fibers in the transverse cerebellar slice to test the effectiveness of low concentrations of WIN55,212-2 in the slice. We loaded bands of parallel fibers with magnesium green and used optical methods to determine the depth of the labeled fibers. We then monitored $\mathrm{Ca}_{\text {influx }}$ in the presence of varying concentrations of the agonist WIN55,212-2. In Figure 1C, parallel fibers running along the very surface of the slice were loaded with magnesium green. Within minutes, $0.1 \mu \mathrm{M}$ WIN55,212-2 substantially decreased $\mathrm{Ca}_{\text {influx }}$. Increasing concentrations of agonist had little additional effect on $\mathrm{Ca}_{\text {influx }}$. However, when fibers $80 \mu \mathrm{m}$ from the surface of the slice were loaded, $0.1 \mu \mathrm{M}$ WIN55,212-2 had no discernible effect after $20 \mathrm{~min}$ (Fig. $1 D$ ). Even in the presence of $10 \mu \mathrm{M}$ WIN55,212-2, almost $40 \mathrm{~min}$ were required to reach a stable baseline despite the nanomolar affinity of WIN55,212-2 for cannabinoid receptors. These results demonstrate that it is impractical to perform a dose-response curve because it is diffi- 

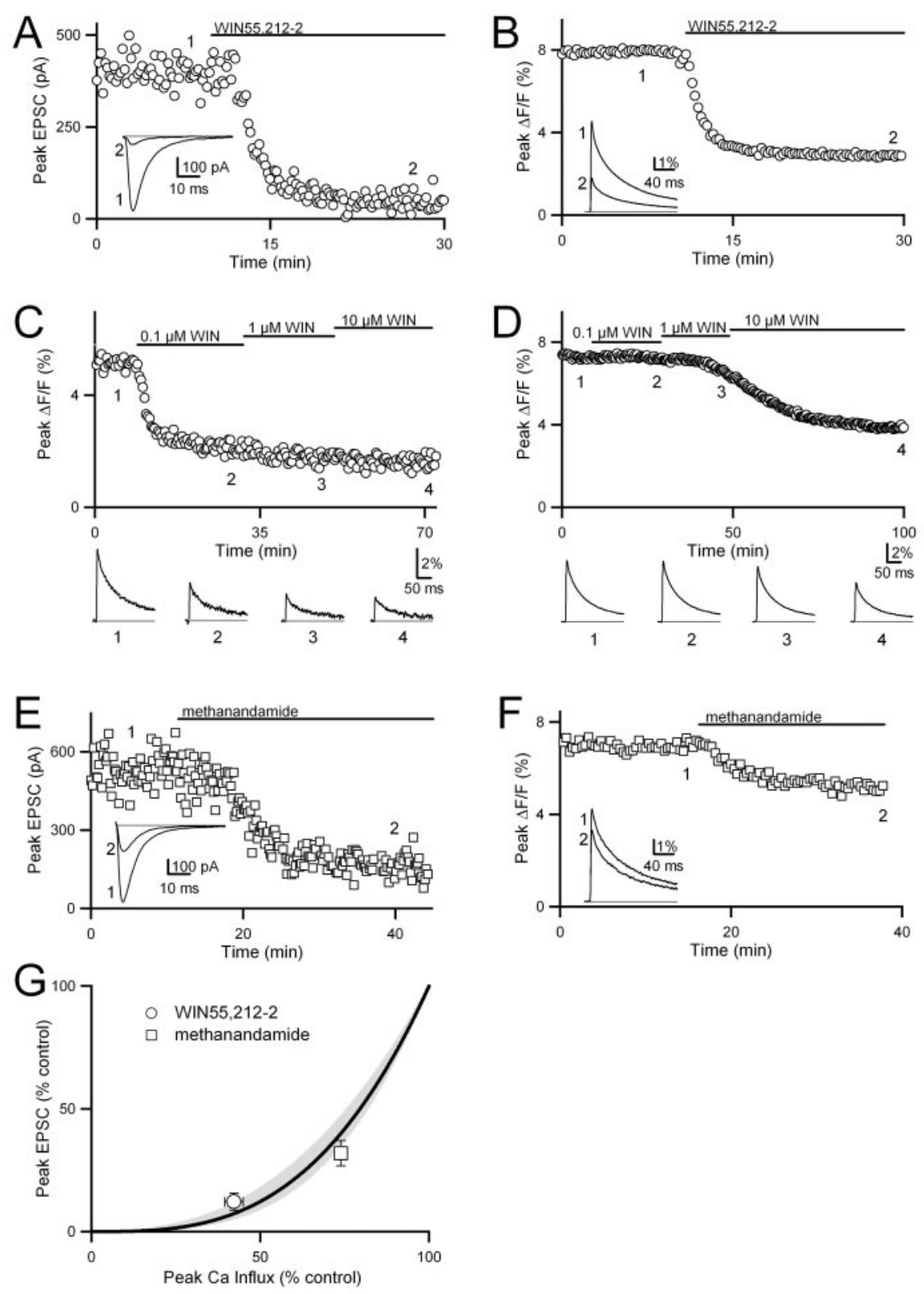

Figure 1. Cannabinoid receptor activation attenuates parallel fiber EPSCs by decreasing presynaptic $C_{\text {influx }}$. $\operatorname{ESSCS}(A, E)$ and presynaptic calcium transients $(B-D, F)$ evoked by single stimulations of the parallel fiber pathway are shown. The cannabinoid receptor agonist WIN55,212-2 $(5 \mu \mathrm{m})$ greatly reduced the amplitudes of both $\operatorname{EPSCS}(A)$ and presynaptic calcium transients $(B)$. $C, D$, The depth of the loaded parallel fibers had a large effect on the time course of inhibition after the bath application of WIN55,212-2. C, The loaded fibers were $\sim 5 \mu \mathrm{m}$ from the surface of the slice; in $D$ they were $\sim 80 \mu \mathrm{m}$ deep in the tissue. Methanandamide $(5 \mu \mathrm{M})$, a partial cannabinoid receptor agonist, modestly reduced parallel fiber EPSCS $(E)$ and presynaptic calcium transients $(F) . G$, The peak EPSC amplitude is plotted as a function of peak presynaptic $\mathrm{Ca}_{\text {influx }}$ in the presence of WIN55,212-2 and methanandamide. The power law relationship between presynaptic $\mathrm{C}_{\text {influx }}$ and EPSC amplitude determined in previous studies (Eq. 1; $n=2.5-3.5$ ) is plotted in gray for the purpose of comparison. A fit to Equation 1 for the methanandamide and WIN55,212-2 points yielded $n=3.0$ (thickline). This fit was determined by using the logarithmic form of the function weighted by the SDs of the EPSCs measured in methanandamide and WIN55,212-2 and constrained to pass through the $(100,100)$ point.

cult to control the concentrations of lipophilic agonists such as WIN55,212-2 within a brain slice.

Therefore, rather than using low concentrations of a full agonist such as WIN55,212-2, we used saturating concentrations of methanandamide, a partial agonist of the CB1 receptor (Pertwee, 1999). Methanandamide ( $5 \mu \mathrm{M})$ reduced both the peak EPSC
(Fig. $1 E$; to $32 \pm 5 \%$ of control; $n=5$ ) and presynaptic $\mathrm{Ca}_{\text {influx }}$ (Fig. $1 F$; to $74 \pm 1 \%$ of control; $n=4)$, but to a lesser extent than WIN55,212-2.

The relationship between EPSC amplitude and $\mathrm{Ca}_{\text {influx }}$ allowed us to determine whether modulation by cannabinoids arises solely from changes in $\mathrm{Ca}_{\text {influx }}$. Previous studies have shown that, when $\mathrm{Ca}_{\mathrm{in}}$ flux is altered at this synapse, the relationship between the amplitude of the EPSC and $\mathrm{Ca}_{\text {influx }}$ is approximated by the expression:

$$
\mathrm{EPSC}=k\left(\mathrm{Ca}_{\text {influx }}\right)^{n},
$$

where $k$ is a constant and $n$ has been determined experimentally to be between 2.5 and 3.5 (Mintz et al., 1995; Dittman and Regehr, 1996; Sabatini and Regehr, 1997; Xu-Friedman and Regehr, 2000). This relationship is indicated by the shaded region of Figure $1 G$. If presynaptic modulation does not simply reduce $\mathrm{Ca}_{\text {influx }}$, the relationship deviates significantly from this line (Dittman and Regehr, 1996). In the extreme in which decreased $\mathrm{Ca}_{\text {influx }}$ was not involved, reductions in EPSC amplitude are not accompanied by change in $\mathrm{Ca}_{\text {influx }}$ (Chen and Regehr, 1997). This corresponds to a vertical line, with $\mathrm{Ca}_{\text {influx }}=100 \%$. If the cannabinoidmediated modulation at this synapse arises solely from alterations in $\mathrm{Ca}_{\text {influx }}$, the relationship between $\mathrm{Ca}_{\text {influx }}$ and release measured in the presence of cannabinoid receptor agonists should fall within this shaded region (Dittman and Regehr, 1996). We found this to be the case, because the relationship between EPSC amplitude and $\mathrm{Ca}_{\text {influx }}$ is well approximated by Equation 1, with $n=3.0$ (Fig. $1 G$, thick line). Because the cannabinoid-mediated changes in EPSC amplitude can be accounted for by the decrease in $\mathrm{Ca}_{\text {influx }}$ (Fig. $1 G)$, these results suggest that cannabinoids inhibit parallel fiber to Purkinje cell synapses entirely by reducing presynaptic $\mathrm{Ca}_{\text {influx }}$.

\section{Cannabinoids do not alter the presynaptic waveform}

Previous studies have shown that presynaptic $\mathrm{Ca}_{\text {influx }}$ can be reduced either by alterations in the waveform of the action potential or by direct modulation of presynaptic calcium channels. Subtle changes in the presynaptic action potential can lead to large changes in presynaptic $\mathrm{Ca}_{\text {influx }}$ (Augustine, 1990; Byrne and Kandel, 1996; Sabatini and Regehr, 1997; Qian and Saggau, 1999; Zucker and Regehr, 2002). This suggests that modulation of potassium channels involved in spike repolarization can regulate synaptic strength. Alternatively, activation of G-protein-coupled recep- 
tors can modulate presynaptic calcium channels directly without affecting the presynaptic waveform (Zucker and Regehr, 2002).

Recent studies have suggested that the cannabinoid-mediated decrease in presynaptic $\mathrm{Ca}_{\text {influx }}$ arises indirectly from modulation of presynaptic potassium channels (Alger et al., 1996; Daniel and Crepel, 2001; Varma et al., 2002; Diana and Marty, 2003). Studies showing that the potassium channel antagonist 4-AP (1 $\mathrm{mM}$ ) prevents CB1-mediated inhibition of $\mathrm{Ca}_{\text {influx }}$ present the strongest evidence for this hypothesis. However, no obvious change in the presynaptic volley, a sensitive means of detecting changes in the presynaptic waveform, has been identified in response to cannabinoid receptor agonists. This calls into question the role of changes in the presynaptic action potential in cannabinoid-mediated inhibition of synaptic transmission (Lenz et al., 1998; Takahashi and Linden, 2000; Daniel and Crepel, 2001).

To clarify the role of potassium channels in the cannabinoid-mediated decrease in presynaptic $\mathrm{Ca}_{\text {influx }}$, we first reexamined the effect of 4-AP on the parallel fiber to Purkinje cell synapse to address several concerns. First, 4-AP itself may affect the presynaptic waveform profoundly and alter calcium signaling in the presynaptic terminal. Under these conditions it may be difficult to examine the mechanisms of cannabinoid action. Second, the original study assessed $\mathrm{Ca}_{\text {influx }}$ evoked by five stimuli at $100 \mathrm{~Hz}$. It is not clear whether parallel fibers can follow this frequency of stimulation faithfully in the presence of 4-AP.

We first assessed the effect of $1 \mathrm{~mm}$ 4-AP on the timing and amplitude of presynaptic $\mathrm{Ca}_{\text {influx }}$ by using the low-affinity calcium-sensitive indicator mag-fura-5 (dissociation constant of $28 \mu \mathrm{M}$ for calcium). 4-AP increased calcium levels to $>25$ times that observed in control conditions (Fig. $2 A$ ). In addition, 4-AP greatly slowed the time course of the calcium signal. The pronounced difference in the time courses of the calcium signal under control conditions and in the presence of 4-AP is underscored by comparing the normalized calcium transients evoked under these two conditions (Fig. $2 B$ ). Summary data from five experiments are shown in Figure $2 C$. The time to peak (which includes $>1 \mathrm{msec}$ for the evoked presynaptic action potential to reach the recording site) increased from $2.3 \pm 0.4 \mathrm{msec}$ in control conditions to $174 \pm 12 \mathrm{msec}$ in the presence of 4 -AP $(n=5)$.

The slow rise time of the calcium signal indicates that $\mathrm{Ca}_{\text {influx }}$ persisted for $>100 \mathrm{msec}$ in the presence of 4 -AP. Furthermore, it suggests that repolarization of the presynaptic action potential might not be complete for $>100 \mathrm{msec}$. To test this hypothesis, we examined the calcium signals evoked by one and two stimuli in control conditions and in the presence of 4-AP. In control con-
B
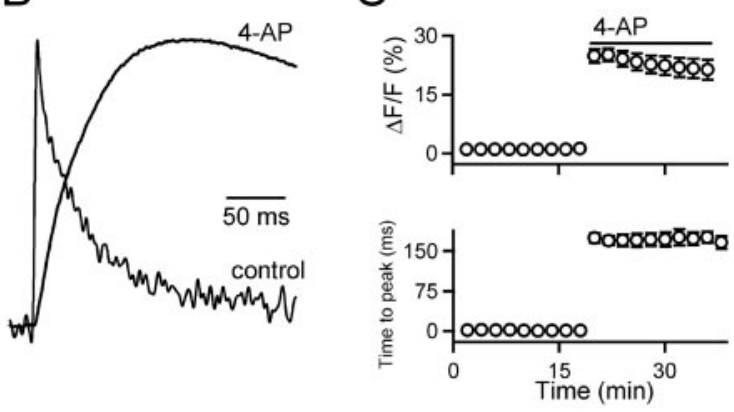

F
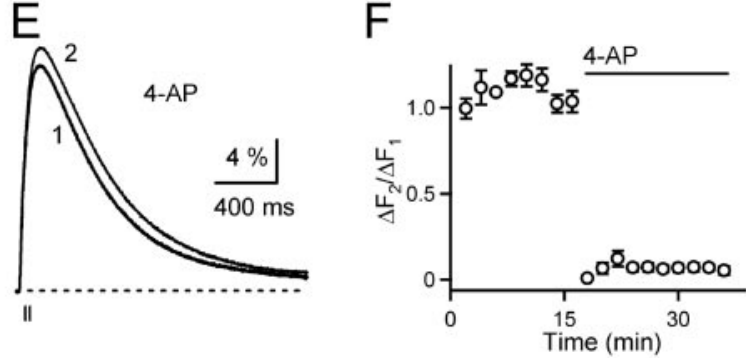

$\mathrm{H}$

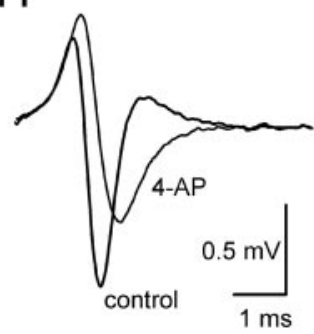

Figure 2. The potassium channel antagonist 4-AP profoundly alters presynaptic calcium signaling. $A$, Representative traces of presynaptic calcium signals evoked by single stimuli quantified with the calcium-sensitive indicator mag-fura-5 are shown on the same scale under control conditions and in the presence of $1 \mathrm{~mm}$ 4-AP. B, Representative traces of presynaptic calcium signals were indicated by vertical bars below the traces. $F$, These results are summarized for five experiments. $G$, Representative traces of the normalized to the values measured before the application of 4-AP. The amplitudes of the first (open squares) and second (open circles) presynaptic volleys were averaged for five experiments.

ditions the incremental increase in fluorescence was similar for a single stimulus and the second of two stimuli $\left(\Delta F_{2} / \Delta F_{1} \approx 1\right.$; Fig. $2 D)$. However, in the presence of 4 -AP the second stimulus generated only a very slight additional increase in fluorescence $\left(\Delta F_{2}\right)$ $\Delta F_{1} \approx 0.07$; Fig. $\left.2 E\right)$. These data are summarized in Figure $2 F$ $(n=5)$. This small incremental increase did not arise from saturation of the calcium indicator, because we used a calcium indicator with a low calcium sensitivity.

Further evidence that 4-AP profoundly alters the presynaptic waveform is suggested by the effect of 4-AP on the presynaptic volley. Under control conditions two stimuli separated by 20 msec evoked presynaptic volleys with the triphasic structure characteristic of a propagating action potential, although the volley activated by the second stimulus was slightly smaller in amplitude (Fig. 2G, top). In the presence of 4-AP the amplitude of the first volley was reduced, and the second volley was virtually eliminated (Fig. $2 G$, bottom). The effects of 4-AP on the ampli- 
tude of the first and second volley are summarized in Figure $2 I$ $(n=4)$. In addition, 4-AP profoundly altered the shape of the first presynaptic volley (Fig. $2 \mathrm{H}$ ).

Taken together, these data indicate that, in the presence of 1 $\mathrm{mM}$ 4-AP, calcium signaling in the presynaptic terminal differs markedly from control conditions. The magnitude of the presynaptic $\mathrm{Ca}_{\text {influx }}$ is increased by $>25$-fold and persists for $\sim 85$ times longer than under control conditions. Furthermore, in 4-AP a second stimulus no longer evokes a presynaptic volley nor causes a significant incremental increase in $\mathrm{Ca}_{\text {influx }}$. These findings suggest that 4-AP prevents spike repolarization for $>100 \mathrm{msec}$. Because the effects of 4-AP on cannabinoid modulation also have been examined in the presence of low external calcium $\left(\mathrm{Ca}_{\mathrm{e}}\right)$, we also characterized the presynaptic calcium signals evoked in 0.1 $\mathrm{mm} \mathrm{Ca}$. We found that in $0.1 \mathrm{~mm} \mathrm{Ca}_{\mathrm{e}}$ the time to peak of the presynaptic calcium signal also was delayed greatly $(89 \pm 10$ msec; $n=4)$. These effects of 4 -AP on presynaptic calcium signaling make it difficult to use 4-AP to examine the mechanism of cannabinoid action.

We therefore took a different approach to assess whether CB1 receptor activation decreased presynaptic $\mathrm{Ca}_{\text {influx }}$ by altering the presynaptic action potential. Previously, we showed that, under appropriate experimental conditions, the time course of presynaptic $\mathrm{Ca}_{\text {influx }}$ is highly sensitive to changes in the presynaptic waveform. Furthermore, the derivative of the presynaptic $\Delta F / F$ signals evoked by a single stimulus provides a good measure of the time course of presynaptic $\mathrm{Ca}_{\text {influx }}$ (Sabatini and Regehr, 1997, 1998). Therefore, if the large decrease in $\mathrm{Ca}_{\text {influx }}$ after $\mathrm{CB} 1$ receptor activation arises from more rapid action potential repolarization and a narrowing of the presynaptic action potential, there should be a substantial effect on the time course of $\mathrm{Ca}_{\text {influx }}$.

Presynaptic calcium transients were measured with the fluorescent calcium indicator magnesium green while the presynaptic volleys were monitored. The effects of WIN55,212-2, the cannabinoid receptor antagonist AM251, and the potassium channel antagonist tetraethylammonium (TEA) then were assessed. TEA was used because it provides a means of broadening the presynaptic action potential in a more controlled manner than is possible with 4-AP (Sabatini and Regehr, 1997). In the representative experiment shown in Figure $3 A$, WIN55,212-2 reduced $\mathrm{Ca}_{\text {influx }}$ to $48 \%$ of control. AM251 reversed this inhibition. Application of TEA $(100 \mu \mathrm{M})$ increased $\mathrm{Ca}_{\text {influx }}$ to $133 \%$ of control. The presynaptic volley was unaffected by CB1 receptor activation (Fig. 3B, middle), whereas TEA altered the volley consistent with an effect on the presynaptic waveform (Fig. $3 B$, right).

The derivative of the fluorescence transients provides a measure of the presynaptic calcium current $\left(I_{\mathrm{Ca}}\right)$. CB1 receptor activation reduced the amplitude of $I_{\mathrm{Ca}}$ without affecting the time course of $\mathrm{Ca}_{\text {influx }}$ (Fig. 3C). On the other hand, TEA increased the total $\mathrm{Ca}_{\text {influx }}$ primarily by broadening the time course of the presynaptic calcium current without affecting the peak of $I_{\mathrm{Ca}}$ (Fig. $3 C)$. Comparing the normalized calcium currents under control conditions and in the presence of WIN55,212-2 highlights the lack of any effect of CB1 receptor activation on the time course of $\mathrm{Ca}_{\text {influx }}$ (Fig. 3D, left). The alteration in the time course of $\mathrm{Ca}_{\text {influx }}$ in TEA is clear (Fig. 3D, right). The average width at halfmaximum $\left(w_{1 / 2}\right)$ of $I_{\mathrm{Ca}}$ was $658 \pm 15 \mu$ sec under control conditions, $655 \pm 21 \mu \mathrm{sec}$ in the presence of WIN55,212-2, and $776 \pm$ $23 \mu \mathrm{sec}$ in the presence of TEA $(n=4)$. Thus, although WIN55,212-2 had a larger effect on total $\mathrm{Ca}_{\text {influx }}$ than did TEA ( $45 \pm 4 \%$ of control compared with $127 \pm 3 \%$ for TEA; $n=4$ ), activation of the CB1 receptor did not alter the half-width of $I_{\mathrm{Ca}}$
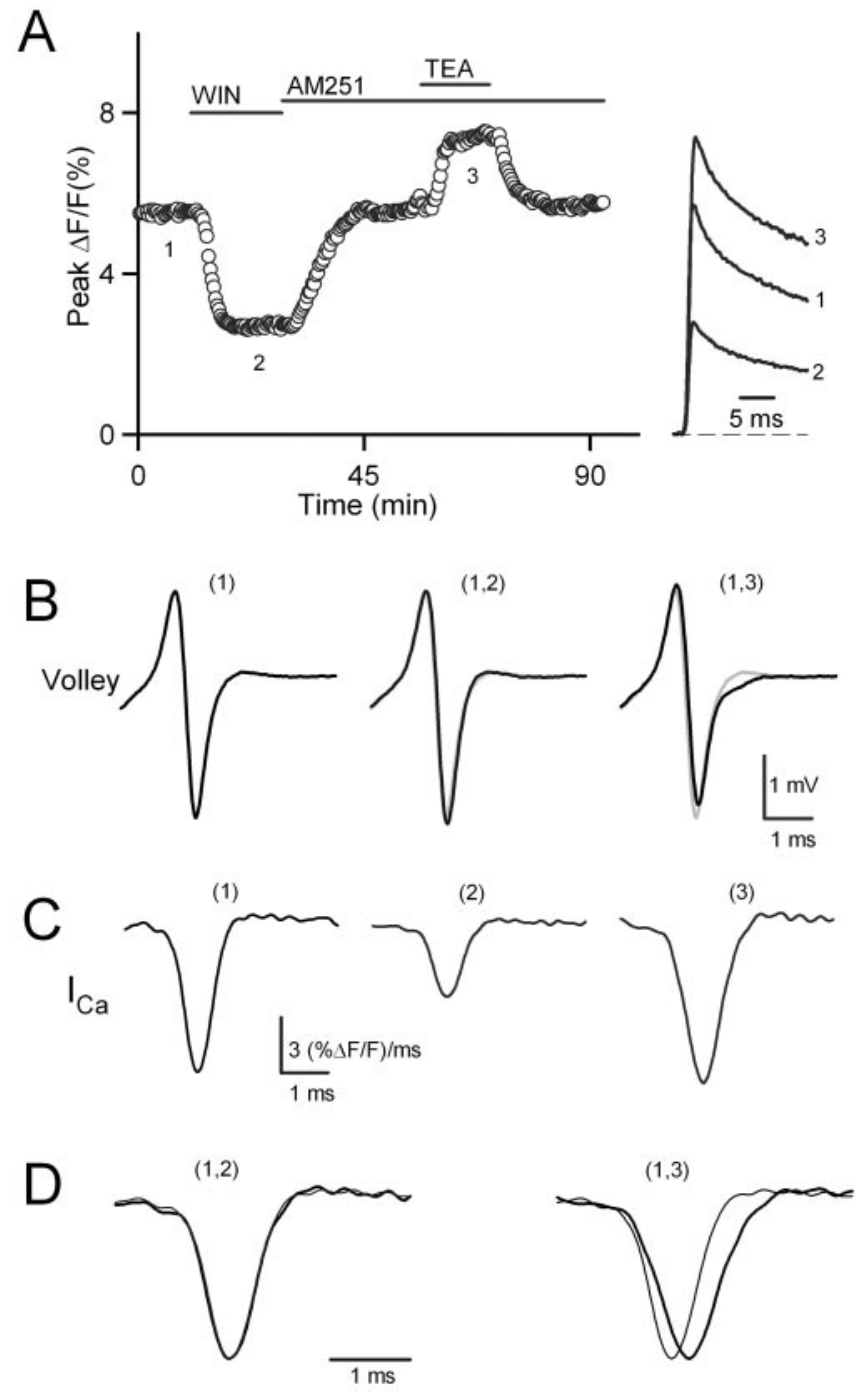

Figure 3. Activation of $\mathrm{CB} 1$ receptors does not affect the time course of presynaptic calcium influx. Fluorescence changes evoked by single stimuli were measured with the calciumsensitive indicator magnesium green and a photodiode with a response time of $3 \mathrm{kHz}$. A, The effects of WIN55,212-2, AM251, and TEA on both the peak $\Delta F / F$ signal (left) and on the time course measured during the indicated times (right) are shown for a representative experiment. In addition, the presynaptic volley was monitored $(B)$ at the times indicated in $A$ (left). $B$, The presynaptic volley is shown under control conditions (left) and in the presence of WIN55,212-2 (middle, black trace) or TEA (right, black trace) as compared with the volley under control conditions (middle and right, gray traces). C, The derivative of the fluorescence transient indicates the time course of presynaptic calcium influx corresponding to $I_{\mathrm{Ca}}$ under control conditions (left) and in the presence of WIN55,212-2 (middle) or TEA (right). D, The time courses of presynaptic calcium influx measured in the presence of WIN55,212-2 (left, bold trace) and in the presence of TEA (right, bold trace) are normalized and compared with control traces (left and right, thin traces).

significantly (Student's $t$ test, $p>0.5$ ), whereas spike broadening with TEA did (Student's $t$ test, $p<0.01$ ).

These findings argue against CB1 receptor activation altering $\mathrm{Ca}_{\text {influx }}$ by affecting the presynaptic action potential. Although the effect of TEA on $\mathrm{Ca}_{\text {influx }}$ was smaller than that of WIN55,212-2, TEA clearly affected the presynaptic volley and the time course of presynaptic calcium entry, whereas WIN55,212-2 did not. Thus we conclude that the cannabinoid-mediated reduction in presynaptic $\mathrm{Ca}_{\text {influx }}$ does not arise from potassium channel modulation. Rather, the decrease in $\mathrm{Ca}_{\text {influx }}$ reflects direct modulation of calcium channels. 
Cannabinoids modulate multiple classes of calcium channels We next examined the classes of presynaptic calcium channels modulated by cannabinoid receptor activation. The three types of calcium channels contributing to neurotransmitter release at the parallel fiber to Purkinje cell synapse are separable pharmacologically: N-type calcium channels correspond to $\mathrm{Ca}_{\mathrm{V}} 2.2$ and are blocked selectively by $\omega$-conotoxin GVIA (CgTx), and P/Q-type channels that correspond to $\mathrm{Ca}_{\mathrm{V}} 2.1$ are blocked selectively by $\omega$-agatoxin IVA (Aga-IVA); the remaining fraction is resistant to both of these toxins (Mintz et al., 1995; Ertel et al., 2000). We refer to this component that is resistant to organic blockers of L-type calcium channels and these peptide toxins as R-type (Randall and Tsien, 1995; Catterall et al., 2003). It is likely that this component is mediated primarily by $\mathrm{Ca}_{\mathrm{V}} 2.3$.

Calcium channel modulation was not restricted to a single class of channels. First we blocked N-type calcium channels with $500 \mathrm{nM}$ CgTx and assessed the effect of WIN55,212-2 on the remaining fraction (Fig. $4 \mathrm{~A}$ ). Cannabinoid receptor activation inhibited $\mathrm{Ca}_{\text {influx }}$ even when $\mathrm{N}$-type calcium channels were blocked, demonstrating that the modulation of calcium channels by cannabinoid receptor activation is not restricted to $\mathrm{N}$-type channels. CgTx alone blocked $25 \pm 2 \%$ of the peak $\mathrm{Ca}_{\text {influx }}$. Coapplication of WIN55,212-2 blocked an additional $38 \pm 3 \%$ of the peak $\mathrm{Ca}_{\text {influx }}$ under control conditions $(n=3)$. WIN55,212-2 also reduced $\mathrm{Ca}_{\text {influx }}$ when $\mathrm{P} / \mathrm{Q}$-type calcium channels were blocked with $200 \mathrm{~nm}$ Aga-IVA (Fig. 4B), indicating that calcium channel modulation similarly is not restricted to P/Q-type channels. Aga-IVA alone blocked $47 \pm 3 \%$ of the peak $\mathrm{Ca}_{\text {influx }}$. Coapplication of WIN55,212-2 blocked an additional $31 \pm 2 \%$ of the peak $\mathrm{Ca}_{\text {influx }}$ under control conditions $(n=3)$. Finally, CgTx and Aga-IVA were coapplied to block N-type and P/Q-type calcium channels simultaneously to assess the effect of WIN55,212-2 on the remaining component mediated by R-type calcium channels. The R-type component clearly was inhibited by activation of cannabinoid receptors (Fig. 4C). The combination of CgTx and AgaIVA reduced peak $\mathrm{Ca}_{\text {influx }}$ by $77 \pm 2 \%$. Coapplication of WIN55,212-2 blocked an additional $11 \pm 1 \%$ of the peak $\mathrm{Ca}_{\text {influx }}$ under control conditions $(n=4)$.

\section{$\mathrm{N}$-type calcium channels are most sensitive to cannabinoid modulation}

To determine the percentage of each calcium channel type modulated by cannabinoid receptor activation, we first applied WIN55,212-2 and then determined the effects of CgTx and AgaIVA on $\mathrm{Ca}_{\text {influx }}$. As shown in a representative experiment, the application of $\mathrm{CgTx}$ and Aga-IVA still reduced $\mathrm{Ca}_{\text {influx }}$ even in the presence of this cannabinoid receptor agonist (Fig. 5).

Using this approach, we quantified the contribution of each type of calcium channel to $\mathrm{Ca}_{\text {influx }}$ in the presence of WIN55,212-2. Expressed as a percentage of total $\mathrm{Ca}_{\text {influx }}$ in control conditions, the $\mathrm{Ca}_{\text {influx }}$ was $8 \pm 1,28 \pm 3$, and $13 \pm 1 \%$ through $\mathrm{N}$-, $\mathrm{P} / \mathrm{Q}-$, and R-type calcium channels, respectively (Fig. $6 A$, black bars; $n=5$ ). In these experiments the sum of the three contributions was $49 \%$, the total $\mathrm{Ca}_{\text {influx }}$ in WIN55,212-2 relative to control. These results are compared with the fraction of $\mathrm{Ca}_{\text {influx }}$ through each channel type in control conditions (Fig. $6 \mathrm{~A}$, open bars). In control conditions the $\mathrm{Ca}_{\text {influx }}$ was $27 \pm 1 \%$ $(n=7), 48 \pm 2 \%(n=7)$, and $23 \pm 3 \%(n=4)$ for N-, P/Q- , and R-type calcium channels, respectively.

We then used these experiments to determine the effect of cannabinoid receptor activation on each component of presynaptic $\mathrm{Ca}_{\text {influx }}$ (Fig. 6). Expressed in terms of the total $\mathrm{Ca}_{\text {influx }}$ in

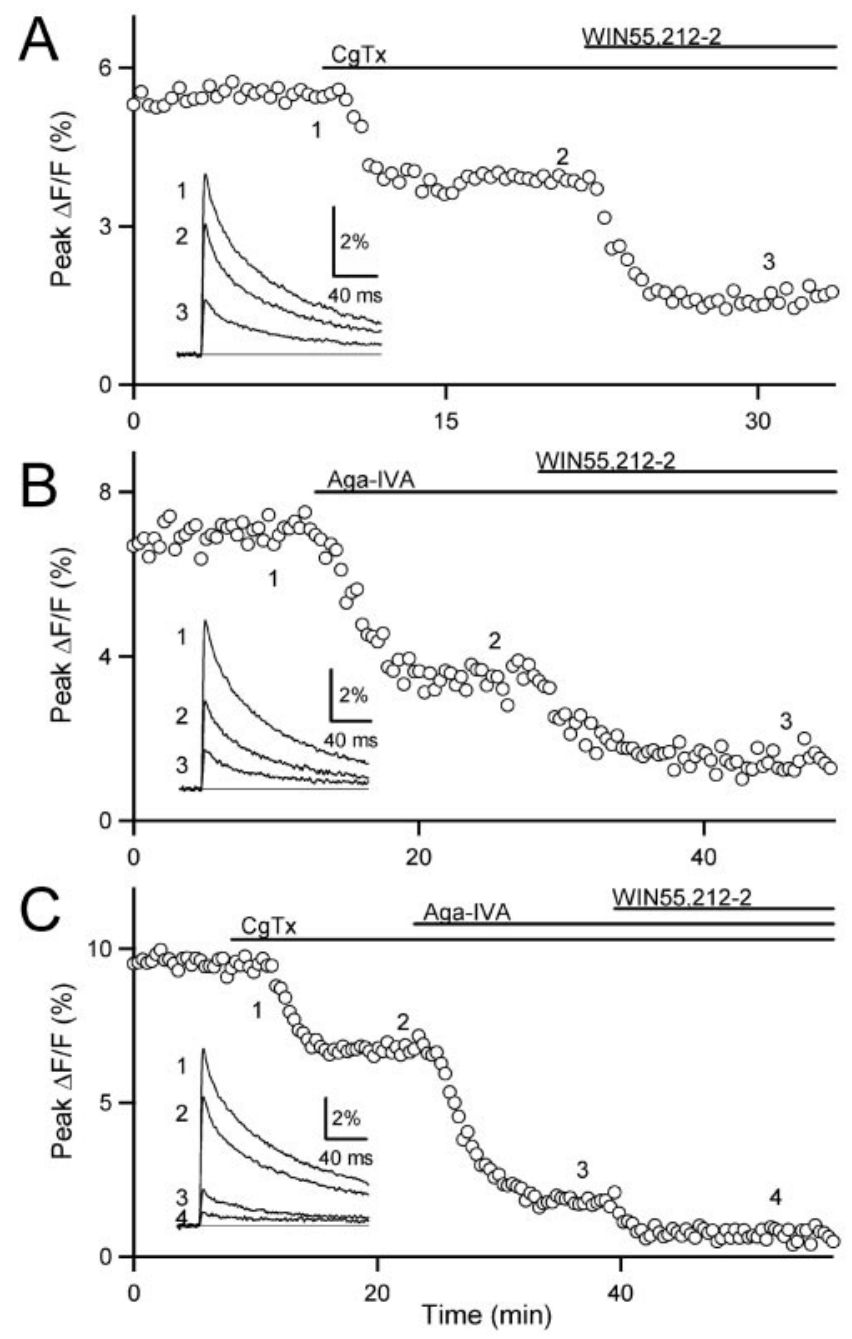

Figure 4. CB1 receptor activation modulates three types of calcium channel at the parallel fiber to Purkinje cell synapse. $A-C$, Representative experiments showing the effects of the cannabinoid receptor agonist WIN55,212-2 (5 $\mu \mathrm{m})$, the N-type calcium channel blocker $\omega$-conotoxin GVIA (CgTx; $500 \mathrm{~nm}$ ), and the P/Q-type calcium channel blocker $\omega$-agatoxin IVA (Aga-IVA; $200 \mathrm{nm)}$ on presynaptic calcium transients. $A$, With CgTx-sensitive channels blocked, application of WIN55,212-2 further decreased $C_{a_{\text {influx }}}$ B, Likewise, with Aga-IVA-sensitive channels blocked, application of WIN55,212-2 further decreased $C_{a_{\text {influx }}}$ C, After the coapplication of C $\mathrm{gTx}$ and Aga-IVA, the application of WIN55,212-2 further inhibited $\mathrm{Ca}_{\text {influx }}$ through the toxin-insensitive channels.

control conditions, the contribution of N-type dropped from $27 \pm 1 \%$ in control conditions to $8 \pm 1 \%$ in the presence of WIN55,212-2. Thus WIN55,212-2 reduced calcium entry through $\mathrm{N}$-type calcium channels by $71 \pm 8 \%(100 \%-8 \% / 27 \%)$ (Fig. 6B). Similar measurements indicated that at this synapse WIN55,212-2 reduced calcium entry through P/Q-type calcium channels by $40 \pm 8 \%$ and through R-type channels by $45 \pm 13 \%$ (Fig. 6B). A comparison of the effect of WIN55,212-2 on the different types of calcium channels revealed that, although there was no significant difference in the modulation of $\mathrm{P} / \mathrm{Q}-$ and R-type calcium channels, $\mathrm{N}$-type channels were inhibited to a greater extent than were either P/Q-type or R-type calcium channels ( $p<0.05$ for both, Student's $t$ test). Therefore, although $\mathrm{N}$-type channels are modulated most strongly by cannabinoid receptor activation, all three calcium channel types found at this synapse are inhibited strongly. 


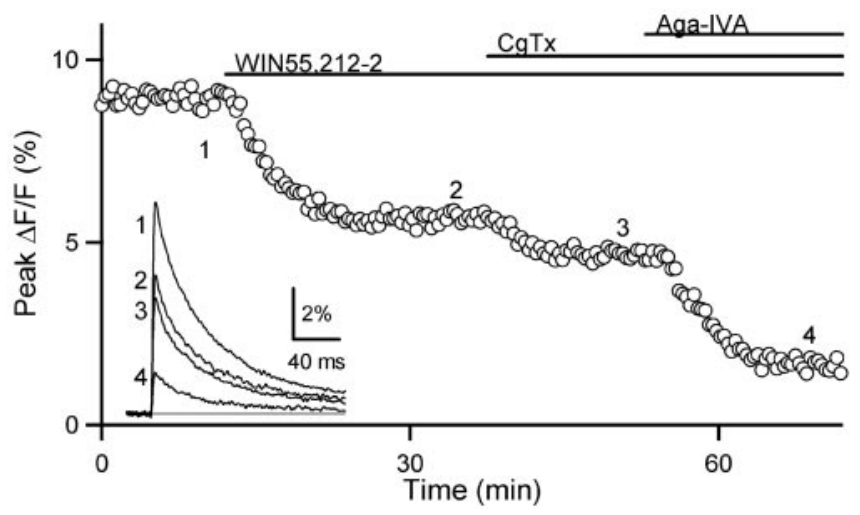

Figure 5. CB1 receptor activation inhibits a subset of each class of calcium channel. After the application of WIN55,212-2, application of CgTx and Aga-IVA each further reduced presynaptic $\mathrm{Ca}_{\text {influx}}$.
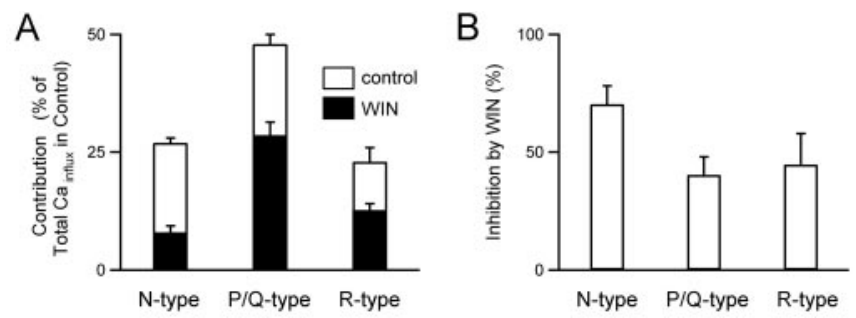

Figure 6. Activation of cannabinoid receptors differentially affects three components of presynaptic calcium influx. $A$, The percentage contribution of each calcium channel type to $\mathrm{Ca}_{\text {influx }}$ in parallel fiber synapses in control conditions (open bars) and in the presence of $5 \mu \mathrm{M}$ WIN55,212-2 (filled bars). Contributions are expressed as the percentage of total $\mathrm{Ca}_{\text {influx }}$ in control conditions. $B$, The percentage of inhibition by WIN55,212-2 of each type of voltagegated calcium channel calculated as described in Results from $A$.

\section{Discussion}

In this study we have clarified the mechanism by which cannabinoids modulate synaptic transmission at the parallel fiber to Purkinje cell synapse. We tested two current hypotheses and found that cannabinoids inhibited transmission neither by modulating potassium channels and narrowing the presynaptic action potential nor by selectively modulating N-type calcium channels. Rather, cannabinoid-mediated inhibition of synaptic transmission reflected presynaptic modulation of all three calcium channel types that underlie transmitter release at this synapse.

\section{Cannabinoids reduce presynaptic calcium entry}

We found that generating dose-response curves with the highly lipophilic cannabinoid receptor agonists and antagonists was impractical in cerebellar brain slices. Optical methods revealed that WIN55,212-2, a widely used cannabinoid agonist, acted slowly and incompletely even at synapses located $<100 \mu \mathrm{m}$ within the slice. These data underscore the limitations of using cannabinoid agonists and antagonists in physiological studies when the depth of the synapses being studied is difficult to control or unknown. These difficulties prevented us from completing a traditional dose-response curve with WIN55,212-2 to determine the relationship between presynaptic $\mathrm{Ca}_{\text {influx }}$ and peak EPSC amplitude. Instead, we quantified the effects on $\mathrm{Ca}_{\text {influx }}$ and the EPSC amplitude of a partial and a full agonist of CB1 receptors. This approach promises to be a generally useful strategy for studying the effects of cannabinoids in brain slices. This approach revealed that the relationship between $\mathrm{Ca}_{\text {influx }}$ and the EPSC amplitude was consistent with cannabinoids decreasing the EPSC amplitude exclusively by inhibiting presynaptic $\mathrm{Ca}_{\text {influx }}$ (Fig. $1 G$ ).

The observation that cannabinoids inhibit transmission at the parallel fiber to Purkinje cell synapse solely by reducing presynaptic calcium entry is consistent with previous studies. First, these studies showed that cannabinoid receptor agonists do not alter the frequency or amplitude of miniature EPSCs at the parallel fiber to Purkinje cell synapse, suggesting that cannabinoid receptor activation does not affect presynaptic processes downstream from calcium entry or postsynaptic AMPA receptor sensitivity (Levenes et al., 1998; Takahashi and Linden, 2000). Second, by monitoring presynaptic $\mathrm{Ca}_{\text {influx }}$ with high affinity indicators, they demonstrated that cannabinoids reduce $\mathrm{Ca}_{\text {influx }}$, although the extent of the reduction could not be quantified (Daniel and Crepel, 2001). Finally, they suggested that cannabinoids acted, at least in part, by modulating presynaptic calcium channels, consistent with our results (Levenes et al., 1998; Takahashi and Linden, 2000).

Cannabinoids do not narrow the presynaptic action potential Previous studies have shown that $1 \mathrm{~mm}$ 4-AP prevents cannabinoid-mediated inhibition of synaptic transmission of parallel fibers (Daniel and Crepel, 2001). These results gave rise to the hypothesis that cannabinoid receptor activation modulates 4-AP-sensitive potassium channels, thereby narrowing the presynaptic action potential and indirectly reducing presynaptic $\mathrm{Ca}_{\text {influx }}$. Several of our experimental findings argue against this hypothesis. First, in $1 \mathrm{~mm} 4$-AP the $\mathrm{Ca}_{\text {influx }}$ increased by $>25$-fold and persisted for $\sim 85$ times longer than under control conditions. Furthermore, in 4-AP a second stimulus was unable to evoke a presynaptic volley. Together these findings suggest that 1 $\mathrm{mM}$ 4-AP may prolong spike repolarization for $100 \mathrm{msec}$, dramatically altering calcium signaling in the presynaptic terminal. Thus our findings suggest that experiments using high concentrations of potassium channel antagonists to study synaptic transmission are difficult to interpret. Second, by measuring the time course of presynaptic calcium entry, we found that cannabinoids do not cause a narrowing of the presynaptic action potential. These findings are consistent with our results and those of previous studies showing that the PF presynaptic volley is unaffected by cannabinoids (Levenes et al., 1998; Takahashi and Linden, 2000). Third, we showed that presynaptic calcium channel types are modulated differentially (see below), which is inconsistent with inhibition arising exclusively from changes in the presynaptic waveform (Sabatini and Regehr, 1997). Finally, we considered the possibility that potassium channel modulation occurs in concert with calcium channel modulation to offset any waveform changes that arise from calcium channel modulation (as might occur if calcium-activated potassium conductances contributed to spike repolarization at this synapse). This seems unlikely because changes in presynaptic calcium entry do not change the presynaptic waveform significantly at this synapse (Sabatini and Regehr, 1997). Thus multiple lines of evidence argue that modulation of presynaptic potassium channels does not contribute significantly to cannabinoid-mediated inhibition of synaptic transmission at this synapse.

\section{Cannabinoids modulate multiple types of calcium channels at this synapse}

We found that cannabinoids modulate all three classes of calcium channels mediating transmitter release at PF terminals. We found that $\mathrm{N}$-type channels are modulated more strongly by cannabi- 
noids than either P/Q-type or R-type channels. However, because calcium flowing through $\mathrm{N}$-type channels accounts for only $\sim 30 \%$ of presynaptic $\mathrm{Ca}_{\text {influx }}$ at PF terminals, modulation of $\mathrm{P} / \mathrm{Q}$ - and R-type channels mediates the bulk of cannabinoidmediated changes in presynaptic $\mathrm{Ca}_{\text {influx }}$ at this synapse. In addition, because P/Q-type calcium channels are particularly effective at evoking release at this synapse (Mintz et al., 1995), modulation of P/Q-type calcium channels likely accounts for most of the cannabinoid-mediated inhibition of the EPSC.

The modulation of N-type, P/Q-type, and R-type calcium channels is consistent with studies in culture and expression systems demonstrating that a variety of voltage-gated calcium channels can be modulated by cannabinoids (Ameri, 1999; Alger, 2002). However, our results differ from those in hippocampal, striatal, and trigeminal neurons, in which blocking presynaptic $\mathrm{N}$-type calcium channels eliminates the effects of cannabinoids (Huang et al., 2001; Wilson et al., 2001; Liang et al., 2004). The difference between these studies and our results simply may reflect the types of channels present in the presynaptic terminals under investigation rather than any selectivity of the cannabinoid signaling system. For example, although three types of calcium channels mediate transmission at parallel fibers, only N-type calcium channels mediate transmission for the class of hippocampal interneurons that express cannabinoid receptors (Katona et al., 1999; Tsou et al., 1999; Wilson et al., 2001; Alger, 2002). Our findings indicate that the hypothesis that cannabinoids exclusively modulate $\mathrm{N}$-type calcium channels in presynaptic terminals does not hold in general. In the specific cases in which it does hold, this specificity may reflect the modulation of the only type of calcium channel present in the presynaptic bouton.

\section{References}

Alger BE (2002) Retrograde signaling in the regulation of synaptic transmission: focus on endocannabinoids. Prog Neurobiol 68:247-286.

Alger BE, Pitler TA, Wagner JJ, Martin LA, Morishita W, Kirov SA, Lenz RA (1996) Retrograde signaling in depolarization-induced suppression of inhibition in rat hippocampal CA1 cells. J Physiol (Lond) 496[Pt 1]:197-209.

Ameri A (1999) The effects of cannabinoids on the brain. Prog Neurobiol $58: 315-348$

Augustine GJ (1990) Regulation of transmitter release at the squid giant synapse by presynaptic delayed rectifier potassium current. J Physiol (Lond) 431:343-364.

Byrne JH, Kandel ER (1996) Presynaptic facilitation revisited: state and time dependence. J Neurosci 16:425-435.

Catterall WA, Striessnig J, Snutch TP, Perez-Reyes E (2003) International Union of Pharmacology. XL. Compendium of voltage-gated ion channels: calcium channels. Pharmacol Rev 55:579-581.

Chen C, Regehr WG (1997) The mechanism of cAMP-mediated enhancement at a cerebellar synapse. J Neurosci 17:8687-8694.

Daniel H, Crepel F (2001) Control of $\mathrm{Ca}^{2+}$ influx by cannabinoid and metabotropic glutamate receptors in rat cerebellar cortex requires $\mathrm{K}^{+}$ channels. J Physiol (Lond) 537:793-800.

Devane WA, Hanus L, Breuer A, Pertwee RG, Stevenson LA, Griffin G, Gibson D, Mandelbaum A, Etinger A, Mechoulam R (1992) Isolation and structure of a brain constituent that binds to the cannabinoid receptor. Science 258:1946-1949.

Diana MA, Marty A (2003) Characterization of depolarization-induced suppression of inhibition using paired interneuron-Purkinje cell recordings. J Neurosci 23:5906-5918.

Diana MA, Levenes C, Mackie K, Marty A (2002) Short-term retrograde inhibition of GABAergic synaptic currents in rat Purkinje cells is mediated by endogenous cannabinoids. J Neurosci 22:200-208.

Di Marzo V, Fontana A, Cadas H, Schinelli S, Cimino G, Schwartz JC, Piomelli D (1994) Formation and inactivation of endogenous cannabinoid anandamide in central neurons. Nature 372:686-691.

Dittman JS, Regehr WG (1996) Contributions of calcium-dependent and calcium-independent mechanisms to presynaptic inhibition at a cerebellar synapse. J Neurosci 16:1623-1633.

Elphick MR, Egertova M (2001) The neurobiology and evolution of cannabinoid signaling. Philos Trans R Soc Lond B Biol Sci 356:381-408.

Ertel EA, Campbell KP, Harpold MM, Hofmann F, Mori Y, Perez-Reyes E, Schwartz A, Snutch TP, Tanabe T, Birnbaumer L, Tsien RW, Catterall WA (2000) Nomenclature of voltage-gated calcium channels. Neuron 25:533-535.

Herrington J, Bookman RJ (1995) Pulse control v4.5: IGOR XOPs for patch-clamp data acquisition. Miami: University of Miami.

Hoffman AF, Lupica CR (2000) Mechanisms of cannabinoid inhibition of $\mathrm{GABA}_{\mathrm{A}}$ synaptic transmission in the hippocampus. J Neurosci 20:2470-2479.

Huang CC, Lo SW, Hsu KS (2001) Presynaptic mechanisms underlying cannabinoid inhibition of excitatory synaptic transmission in rat striatal neurons. J Physiol (Lond) 532:731-748.

Katona I, Sperlagh B, Sik A, Kafalvi A, Vizi ES, Mackie K, Freund TF (1999) Presynaptically located $\mathrm{CB} 1$ cannabinoid receptors regulate GABA release from axon terminals of specific hippocampal interneurons. J Neurosci 19:4544-4558.

Kreitzer AC, Regehr WG (2001a) Retrograde inhibition of presynaptic calcium influx by endogenous cannabinoids at excitatory synapses onto Purkinje cells. Neuron 29:717-727.

Kreitzer AC, Regehr WG (2001b) Cerebellar depolarization-induced suppression of inhibition is mediated by endogenous cannabinoids. J Neurosci 21:RC174(1-5).

Kreitzer AC, Regehr WG (2002) Retrograde signaling by endocannabinoids. Curr Opin Neurobiol 12:324-330.

Lenz RA, Wagner JJ, Alger BE (1998) N- and L-type calcium channel involvement in depolarization-induced suppression of inhibition in rat hippocampal CA1 cells. J Physiol (Lond) 512:61-73.

Levenes C, Daniel H, Soubrie P, Crepel F (1998) Cannabinoids decrease excitatory synaptic transmission and impair long-term depression in rat cerebellar Purkinje cells. J Physiol (Lond) 510:876-879.

Liang YC, Huang CC, Hsu KS, Takahashi T (2004) Cannabinoid-induced presynaptic inhibition at the primary afferent trigeminal synapse of juvenile rat brainstem slices. J Physiol (Lond) 555:85-96.

Maejima T, Ohno-Shosaku T, Kano M (2001) Endogenous cannabinoid as a retrograde messenger from depolarized postsynaptic neurons to presynaptic terminals. Neurosci Res 40:205-210.

Mintz IM, Sabatini BL, Regehr WG (1995) Calcium control of transmitter release at a cerebellar synapse. Neuron 15:675-688.

Ohno-Shosaku T, Maejima T, Kano M (2001) Endogenous cannabinoids mediate retrograde signals from depolarized postsynaptic neurons to presynaptic terminals. Neuron 29:729-738.

Pertwee RG (1999) Pharmacology of cannabinoid receptor ligands. Curr Med Chem 6:635-664.

Qian J, Saggau P (1999) Modulation of transmitter release by action potential duration at the hippocampal CA3-CA1 synapse. J Neurophysiol $81: 288-298$.

Randall A, Tsien RW (1995) Pharamcological dissection of multiple types of $\mathrm{Ca}^{2+}$ channel currents in rat cerebellar granule neurons. J Neurosci 15:2995-3012.

Regehr WG (2000) Monitoring presynaptic calcium dynamics with membrane-permeant indicators. In: Imaging neurons: a laboratory manual (Yuste R, Lanni F, Konnerth A, eds), pp 37.1-37.11. Cold Spring Harbor, NY: Cold Spring Harbor Laboratory.

Regehr WG, Mintz IM (1994) Participation of multiple calcium channel types in transmission at single climbing fiber to Purkinje cell synapses. Neuron 12:605-613.

Robbe D, Alonso G, Duchamp F, Bockaert J, Manzoni OJ (2001) Localization and mechanisms of action of cannabinoid receptors at the glutamatergic synapses of the mouse nucleus accumbens. J Neurosci 21:109-116.

Sabatini BL, Regehr WG (1997) Control of neurotransmitter release by presynaptic waveform at the granule cell to Purkinje cell synapse. J Neurosci 17:3425-3435.

Sabatini BL, Regehr WG (1998) Optical measurement of presynaptic calcium currents. Biophys J 74:1549-1563.

Stella N, Schweitzer P, Piomelli D (1997) A second endogenous cannabinoid that modulates long-term potentiation. Nature 388:773-778.

Sullivan JM (1999) Mechanisms of cannabinoid receptor-mediated inhibi- 
tion of synaptic transmission in cultured hippocampal pyramidal neurons. J Neurophysiol 82:1286-1294.

Takahashi KA, Linden DJ (2000) Cannabinoid receptor modulation of synapses received by cerebellar Purkinje cells. J Neurophysiol 83:1167-1180.

Tsou K, Mackie K, Sanudo-Pena MC, Walker JM (1999) Cannabinoid CB1 receptors are localized primarily on cholecystokinin-containing GABAergic interneurons in the rat hippocampal formation. Neuroscience 93:969-975.

Varma N, Brager D, Morishita W, Lenz RA, London B, Alger B (2002) Presynaptic factors in the regulation of DSI expression in hippocampus. Neuropharmacology 43:550-562.

Wilson RI, Nicoll RA (2001) Endogenous cannabinoids mediate retrograde signaling at hippocampal synapses. Nature 410:588-592.
Wilson RI, Nicoll RA (2002) Endocannabinoid signaling in the brain. Science 296:678-682.

Wilson RI, Kunos G, Nicoll RA (2001) Presynaptic specificity of endocannabinoid signaling in the hippocampus. Neuron 31:453-462.

Xu-Friedman MA, Regehr WG (2000) Probing fundamental aspects of synaptic transmission with strontium. J Neurosci 20:4414-4422.

Yoshida T, Hashimoto K, Zimmer A, Maejima T, Araishi K, Kano M (2002) The cannabinoid CB1 receptor mediates retrograde signals for depolarization-induced suppression of inhibition in cerebellar Purkinje cells. J Neurosci 22:1690-1697.

Zucker RS, Regehr WG (2002) Short-term synaptic plasticity. Annu Rev Physiol 64:355-405. 